\title{
Extracts from the Presidential Address to the International Society of Clinical Pathology meeting in Rome
}

Professor Maurice Welsch (Liège) opened the Congress, and the following are extracts from his speech which he delivered in Italian, French, and English.

'In the name of all the member societies affiliated to the International Society of Clinical Pathologists and on my own behalf I wish to express our most profound and sincere gratitude to the many distinguished persons-diplomatic, civil, military, and scientific - who have done us the great honour of being present at our inaugural ceremony. Their presence here bears witness to their concern for the health of the people and for the work of those whose vocation it is to ensure and improve it. For us as specialists in clinical pathology, who labour so that the diagnosis of illness may become every day more precise, more certain, and more rapid, and that research into the evolution of disease and the orientation and control of therapy should be more vigorous and efficacious, your presence here is an encouragement and, at the same time, a mark of sympathy and confidence which we indeed appreciate.

'In the name of those who specialize in clinical pathology and have come here from all over the world to the sixth Congress, I should like to express on their behalf our warmest thanks to the Italian Society of Clinical Pathology....

'Our gratitude goes particularly to the Organizing Committee, who were charged with the task of planning the scientific sessions and the social activities in which we shall participate this week. It is hardly possible for me to describe the part taken by each member of the Committee in ensuring the success of the Congress, but I cannot let pass in silence the unceasing efforts of the President [Professor de Sanctis Monaldi] in planning this international meeting in a fashion which appeared to him worthy of the importance both of clinical pathology and of traditional Roman hospitality.

'Let me finally be permitted to say to the Secretary General how conscious we are of the time and energy which he has spent, without counting the cost, in organizing the congress. His role as coordinator and executive officer of the Committee was certainly no sinecure. To build a programme which is well-balanced, in such a vast and complex field as clinical pathology, so as to retain the interest of all those taking part and, at the same time, to bring to those who work in the most specialized fields new facts and new points of view; to choose the best "rapporteurs" and to define with each the scope of his paper to the last detail, and persuade him to send his manuscript within the time limits imposed by the printers; to collect and distribute within their sections the free communications; and to foresee all the practical problems indispensable to the good organization of the sessions. All that, and much else which I have not mentioned, is the unrewarding task of a Secretary General, and represents ceaseless work and innumerable problems.

'Technically highly diversified, clinical pathology finds unity in its final aim, the study of clinical problems of which the solution is for the highest benefit of the sick. This common objective gives to clinical pathologists-whether they are primarily trained as anatomists, biochemists, microbiologists, or haematologists - an identical way of thinking about their problems and seeking their solutions. This common outlook explains why it is so important that clinical pathologists should meet regularly to discuss the many-sided questions specific to applied pathology and its evolution as well as the function and status of the clinical pathologist in a changing world.

'However, the many methods of clinical pathology have greatly changed since the foundation of the International Society, and, moreover, differently in different countries, but whether the task of the consultant is conducted by independent individuals, specializing in particular disciplines, or whether it is entrusted to a team of specialists cooperating closely or in the last resort the task is carried out by a single medical specialist assisted by technicians not medically qualified, we must reassure ourselves that the role of the doctor specializing in clinical pathology is not, either exclusively or even preponderantly, that of an administrator. His training in the domain of clinical practice and of pathology in the widest sense and his knowledge of the great resources that the laboratory offers must make the pathologist a real adviser to the clinician even in circumstances of great difficulty. In a clinical context, the pathologist should be able to suggest the execution of this or that 
analysis and the choice of one method or another. Moreover, his intervention will be necessary to arrive at a correct interpretation of the results given by the laboratory tests. The number of tests used for clinical diagnosis and their growing complexity ensures in fact that clinicians, except in the great specialized hospitals, have more and more need of a consultant in clinical pathology. The consequences of this evolution on the structure and future activities of our Society will be discussed in the course of this Congress and undoubtedly will not be one of the subjects of least interest.' 